\title{
GENDER AND JOB SATISFACTION IN HIGHER EDUCATION INSTITUTION: CASE STUDY FROM UZBEKISTAN
}

\author{
Olesya Smagina \\ Westminster International University in Tashkent, Uzbekistan
}

\begin{abstract}
The purpose of this research is to explore the relationship between gender and job satisfaction, as well as its factors. The case study was conducted among academic and administrative staff at a university environment, to identify factors contributing to job satisfaction and their importance for female and male employees. Overall, there were 102 returned questionnaires and 20 interviews with academic and administrative employees.

The relationships between gender and job satisfaction factors were found for specific factors such as personal workspace and job security. T-tests identified statistical significance for differences in satisfaction with personal workspace, relationship with co-workers, and support for training and development factors. Besides, more females are concerned with flexibility at work than males.
\end{abstract}

Keywords: job satisfaction, factors, gender, males and females, university, flexibility

DOI: http://dx.doi.org/10.15549/jeecar.v7i2.392

\section{INTRODUCTION}

Sabharwal and Corley (2009) emphasized that university management and education policymakers need to examine job satisfaction among their employees. Okpara et al. (2005) stated that appreciation of the factors involved in job satisfaction is crucial for improving happiness and addressing the diversity of the staff. Work expectations and experiences are different for males and females, taking into consideration social and cultural norms that prescribe certain roles and behaviours to a particular gender. Men and women encounter diverse "social and organizational dilemmas in a complex environment” (Reed et al., 1994, p. 32). They have various sets of routines that are conditioned by job and home demands, as well as personal characteristics and needs.
Consequently, gender-related issues and job satisfaction have become an area for many research projects with extensive debates in the literature. Employees may have different attitudes towards work, and job satisfaction of males and females may differ due to various factors attributed by the organizations. Several studies suggested that factors that influence job satisfaction are perceived differently by males and females (Lacy \& Sheehan, 1997; Okpara et al., 2005; Schulze, 2006; Fako et al., 2009). This research project aims to explore job satisfaction and contributing factors for male and female employees.

\section{LITERATURE REVIEW}

Job satisfaction is a multidimensional construct that is essential for the improvement 
of organizational performance and competitiveness (Mustapha \& Ghee, 2013). Exploring job satisfaction can reveal employees' feelings about their job and can lead to a lower level of turnover and absenteeism (Mustapha \& Ghee, 2013), higher organizational effectiveness, and organizational commitment (Abdulla et al., 2011). Luthans (1998) stated that there are three fundamental dimensions in job satisfaction: the emotional response to a job situation, whether the expectations are met or exceeded, and the attitudes related to features of the job (nature of the work, promotion opportunities, supervision and colleagues). Herzberg (1959) introduced a two-factor theory explaining job satisfaction phenomena. Motivators or intrinsic factors such as growth, advancement and work itself are contributors to job satisfaction. Hygiene factors such as salary, status, security and administration can lead to dissatisfaction (cited in Toker, 2011).

Numerous studies (Oshagbemi, 2000; Okpara et al., 2005; Saner \& Eyupoglu, 2012; Toker, 2011) investigated the role of job satisfaction and its factors for university employees. Saba (2011), in the study of a Pakistani university, found that the nature of work, salary, coworkers, promotion opportunities, job security and working conditions were the significant factors for determining job satisfaction or dissatisfaction. The study conducted at the South African universities by Schulze (2006) reported more specific factors of academic staff job satisfaction that can be commonly found in other institutions. The aspects and examples that lead to dissatisfaction are listed in Table 1 below.

Table 1. Causes of dissatisfaction for academic staff

\begin{tabular}{|l|l|}
\hline Causes of Dissatisfaction & Examples \\
\hline Inferior quality of students' work & $\begin{array}{l}\text { Lack of time to do research, shortage of research } \\
\text { assistants, uncertainty about how to do research, } \\
\text { and the quality of their research efforts }\end{array}$ \\
\hline Aspects related to research & $\begin{array}{l}\text { Lack of clear procedures } \\
\text { Amount of paperwork involved and the level of } \\
\text { interaction at meetings }\end{array}$ \\
\hline Promotion process & Administrative work aspects \\
\hline $\begin{array}{l}\text { Interpersonal communication with other } \\
\text { colleagues }\end{array}$ & \\
\hline $\begin{array}{l}\text { Not enough funding to go to conferences of recognition for work within the } \\
\text { institution }\end{array}$ & \\
\hline
\end{tabular}

Adapted from Schulze (2006), p. 333

Oshagbemi (1997, cited in Schulze, 2006) elaborated on the reasons for academic staff dissatisfaction that were brought up: a substantial increase of students in classes, ineffective course evaluation procedures, insignificant acknowledgment of teaching skills, excessive marking, and emphasis on research at the expense of teaching. Schulze (2006) further commented on the satisfiers that included cultivating positive relationships among coworkers, aligning the interests of subjects and courses they wanted to teach, ensuring

flexibility, academic autonomy, and rights to choose the direction of their own research. Universities can benefit from appreciating the factors contributing to job satisfaction and need to design mechanisms to support retention of academic talents (Mustapha \& Ghee, 2013) that will lead to a higher standard of teaching and yield good quality research and publications (Duong, 2014).

Many scholars (Bay et al., 2001; Okpara et al., 2005; Abosode, 2014; Hundera, 2014; etc.) 
examined the relationships between gender and job satisfaction; however, many of them presented contradictory results (Oshagbemi, 2000). Toker (2011) compared means of job satisfaction and concluded that gender and marital status did not have significant relationships to job satisfaction. Nevertheless, some of the indicators proved that female academic staff demonstrated higher levels of job satisfaction in the evaluation of relationships with colleagues, and promotion opportunity, compared to male academics. The study also revealed less appreciation for female teachers than for their male counterparts, considering the factor of employee supervision (Hundera, 2014). Furthermore, Singh et al. (2004), Soleman (2005), Collins \& Helen (2013, cited in Yapa et al., 2014) did not find any significant differences in job satisfaction based on gender. This can be explained by a specific difficulty to capture objective attitudes of employees about their job satisfaction. Mangi et al. (2011) discovered one of the possible reasons for a threat to objectivity, reporting a significant number of female faculty members who "have remained undecided regarding various factors of job satisfaction" (p. 87). Namely, in our society, the female members of staff "do not always show their true opinion about the level of job satisfaction" (Mangi et al., 2011, p. 87).

Nevertheless, several research projects established that gender has an impact on the level of job satisfaction, and female teachers are more satisfied than male ones (Pandey, 2014; Saner \& Eyupoglu, 2012; Oshagbemi, 2000; Kinman, 1998 cited in Okpara et al., 2005). The differences in job satisfaction between genders were also found in early research, which demonstrated that women were less satisfied with their jobs than men (Smith et al., 1969 cited in Yapa et al., 2004). Abosede (2010) found that there were significant differences in perceived job satisfaction between male and female teachers, and job satisfaction was found to be higher for female colleagues. On the other hand, some studies confirmed the opposite (Sabharwal \& Corley, 2009;), and concluded that males were more satisfied than females in their work.

The levels of job satisfaction can be dissimilar for both genders, and the variances can be justified because women and men have diverse levels of expectations at work and distinct standards for evaluating work and use of opportunities. Meanwhile, career is mostly a key for men as breadwinners rather than for women (Kim, et al., 2009 cited in Hundera, 2014), and working women may encounter negative attitudes from husbands or family members (Millier \&Bellamy, 2014). The example from the US data acknowledged that men and women had different attitudes toward job flexibility (Bender et al., 2005). Even though men and women take into consideration the same dimensions, the extent to which each dimension has influence can be different for both genders (Garcia- Bernal et al., 2005). For instance, Lacy and Sheehan (1997), who explored job satisfaction across eight nations, found that female academics from Israel and Hong Kong were slightly more satisfied with their relationship with colleagues than their male colleagues were (Ibid). Furthermore, the same study in Australia and Israel confirmed the differences in job satisfaction, and females were considerably more satisfied than their male colleagues were in the aspect mentioned above regarding their job.

Variances in job satisfaction between males and female staff are due to negative work experiences such as gender discrimination, nepotism and favouritism, stress evoked by supervisors, overload, and domestic responsibilities (Fako et al., 2009). These negative experiences resulted in a lower level of satisfaction among females than among males (Fako et al., 2009). Machado-Taylor et al. (2014) concluded that females were less happy with personal and professional growth, as it is difficult to accommodate the balance between work and family. Different roles in life, such as being a wife and a mother, placed females in two conflicting demands - their job demands and their family duties. At the same time, most male academics do not have these supplementary family responsibilities (Okpara et al., 2005). As a result of the mix of family and professional responsibilities, women are often overworked and exhausted, which may hinder their teaching and professional performance and affect job satisfaction. Reed et al. (1994) argued that it is difficult "to develop suitable mechanisms to cope with role conflicts that 
arise, particularly for women, between family and career" (p. 32). It was supported by Fako et al. (2009) whose study determined that married male university employees were more satisfied with their jobs than their married female colleagues.

Hence, the findings of previous research into the relationship between gender and job satisfaction are mixed and inconsistent. Therefore, replicating the study on academic and administrative staff job satisfaction and the effect of gender will contribute more to the understanding of the complex construct of job satisfaction. That is why university managers need to detect factors and create conditions to improve the levels of job satisfaction among their workers (Fako et al., 2009). Lacy and Sheehan (1997) recommended to university managers, who want to encourage higher levels of job satisfaction that they must consider the working environment. As it is recommended by Fako et al. (2009), it is crucial to occasionally take a "snapshot of the extent of job satisfaction among employees of major organizations, especially after major changes are introduced in the organization" (p. 406). As it has been mentioned above, a few studies were conducted on academic and non-academic staff job satisfaction, although hardly any in Uzbekistan. University $\mathrm{X}$ is chosen as a case to explore job satisfaction.

\section{METHODOLOGY}

This paper aims to analyse the factors that contribute to job satisfaction of university employees and discuss the relationships of gender and job satisfaction factors for academic and administrative staff at university X. Figure 1 was compiled to demonstrate the framework of the study with the research questions and hypothesis below:

Research Question 1: What is the relationship between gender and job satisfaction of university staff?

1:H0: There is no relationship between gender and job satisfaction of university staff.

1:H1: There are relationships between gender and job satisfaction of university staff.

Research Question 2 What is the relationship between gender and factors contributing to job satisfaction of university staff?

2:H0: There is no relationship between gender and factors contributing to job satisfaction of university staff.

2:H1: There are relationships between gender and factors contributing to job satisfaction of university staff.

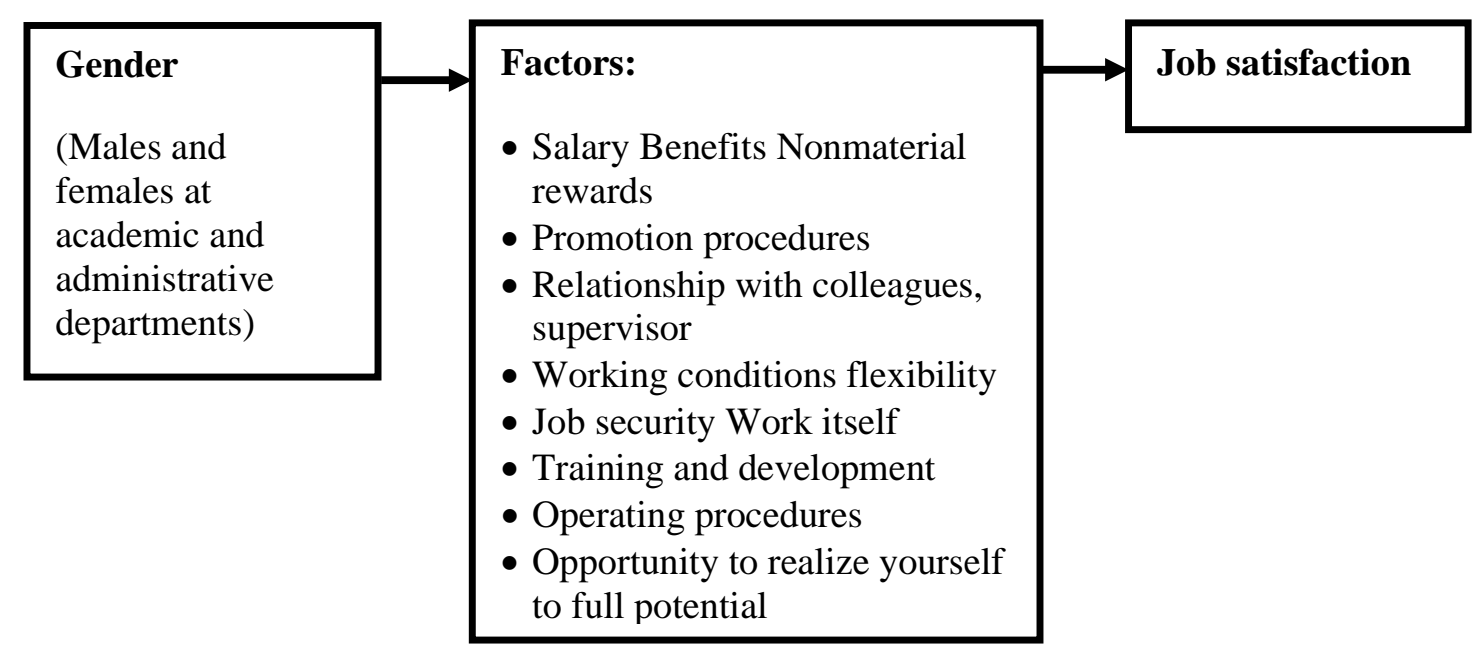

Figure 1: Gender - job satisfaction and factors framework

Research instruments were semi-structured interviews and internet-mediated questionnaires to gather qualitative data and quantitative data. Semi-structured interviews with open questions were held at the exploratory stage of summarizing factors and 
determining their importance for both academic and administrative staff by gender. Respondents were also asked to provide recommendations to enhance their job satisfaction.

A Chi-square test was employed to find out if there are relationships between the dependent variable of job satisfaction and gender as an independent variable. Mean differences for job satisfaction and its factors were compared with the help of t-tests run by SPSS software, Version 20. The analysis of the recommendations to improve job satisfaction was performed via qualitative and mixed-method software QDA Miner 4 that assisted in making chi-square tests for recommendations and gender.

There were ten males and ten females interviewed about job satisfaction. The job satisfaction questionnaire obtained results from 102 employees, out of which 43 were females and 59 were males. The survey was responded by $55 \%$ of total academic staff and $42 \%$ of administrative staff. The response rate was considered sufficient for the study, but it was lower than expected. The reason is that the study was conducted during the summertime when many employees go on vacation. In the sample, there were $35 \%$ members from administrative staff and 65\% from academic staff. The administrative staff contained $39 \%$ of females and $61 \%$ of males. In comparison, the academic group consisted of $44 \%$ of females and $56 \%$ of males that corresponded to the share of the male (60\%) and female (40\%) staff at university.

\section{RESULTS AND DISCUSSION}

During the interview, employees were asked to elaborate on the factors of their job satisfaction. Figure 2 demonstrates the frequency of keywords in interviews related to job satisfaction factors.

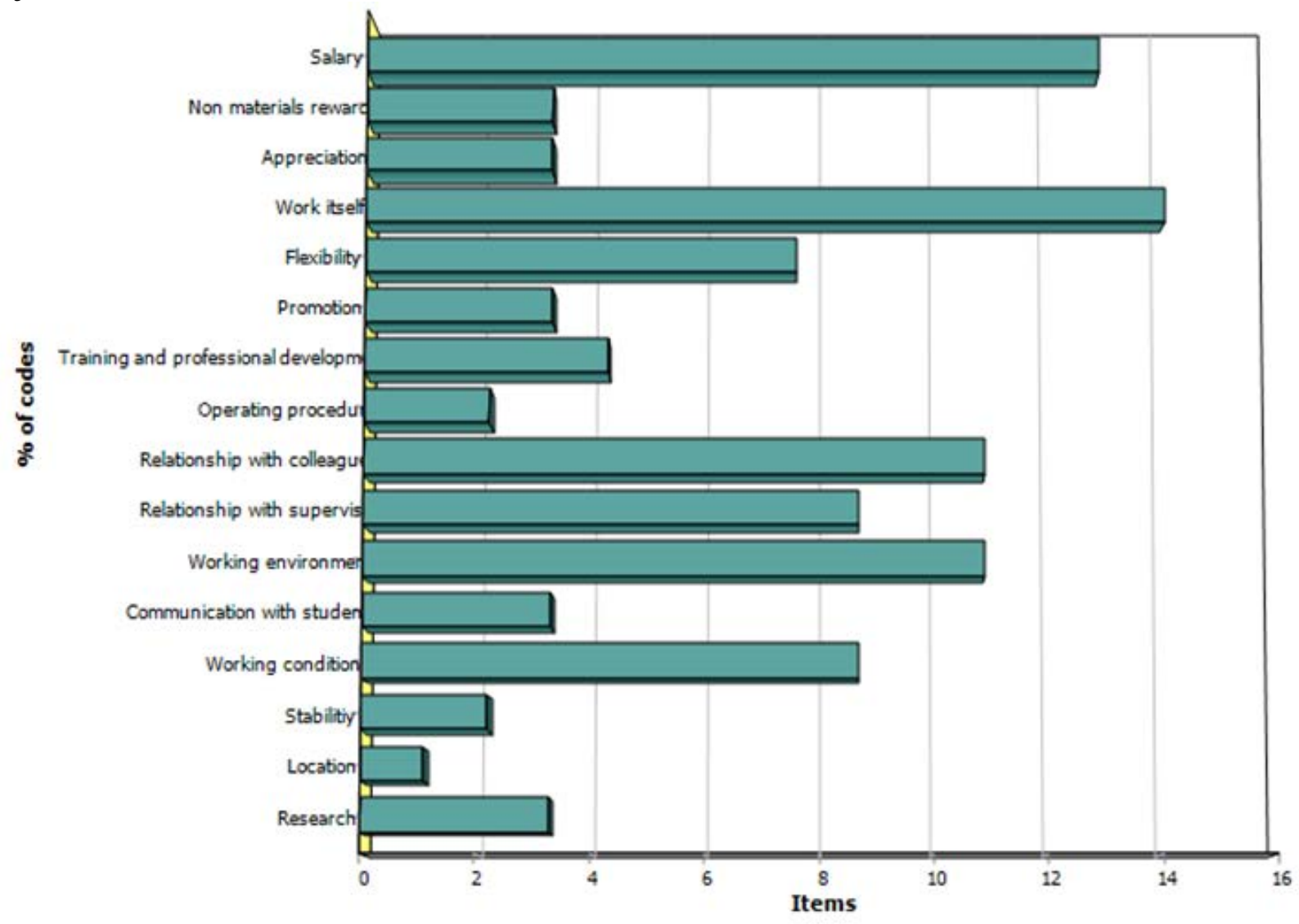

Figure 2: Distribution Frequency of keywords in \% regarding the importance of factors in interview findings (QDA Miner) 
Firstly, in the interviews, respondents mentioned that they enjoyed their work and considered it as interesting and challenging, i. e. more than $14 \%$ of codes identified work itself as the most significant factor. It helped them to stimulate their motivation and was attributed as an essential factor. Secondly, the salary was discussed in $12.5 \%$ of codes as the other significant factor. Thirdly, relationships with colleagues and a favourable working environment at the university were appraised as weighty factors for the respondents. Working conditions and relationships with supervisors had a similar number of frequencies and outscored flexibility, training and development, and research.

Table 2 indicates the code frequencies based on gender variable, tabulated by rows. Males expressed more preferences on the importance of salary, training and professional development, location, as well as a relationship with supervisor and research related aspects. At the same time, females took into consideration non-material rewards, appreciation, nature of work, promotion, relationship with colleagues, flexibility, and communication with students and stability.

Table 2: Gender and the important factors (QDA Miner)

\begin{tabular}{|l|l|l|}
\hline Factors & Male & Female \\
\hline Salary & $58.30 \%$ & $41.70 \%$ \\
\hline Non material rewards & $33.30 \%$ & $66.70 \%$ \\
\hline Appreciation & $20.00 \%$ & $80.00 \%$ \\
\hline Work itself & $33.30 \%$ & $66.70 \%$ \\
\hline Flexibility & $48.00 \%$ & $52.00 \%$ \\
\hline Promotion & $33.30 \%$ & $66.70 \%$ \\
\hline Training and professional development & $75.00 \%$ & $25.00 \%$ \\
\hline Operating procedure & $50.00 \%$ & $50.00 \%$ \\
\hline Relationship with colleagues & $45.00 \%$ & $55.00 \%$ \\
\hline Relationship with supervisor & $55.00 \%$ & $45.00 \%$ \\
\hline Working environment & $50.00 \%$ & $50.00 \%$ \\
\hline Communication with students & $20.00 \%$ & $80.00 \%$ \\
\hline Working conditions & $50.00 \%$ & $50.00 \%$ \\
\hline Stabilitiy & $20.00 \%$ & $80.00 \%$ \\
\hline Location & $80.00 \%$ & $20.00 \%$ \\
\hline Research & $66.70 \%$ & $33.30 \%$ \\
\hline
\end{tabular}

The interview results of 20 members of staff revealed that most of them were satisfied with their job, evaluating their satisfaction from the "satisfied to a certain extent" to "satisfied completely." Only three respondents revealed present dissatisfaction, which was connected with the nature of work and intense workload. They also commented on the unequal distribution of duties and burnout at work. Other respondents who were satisfied commented on interesting reasons for their satisfaction, such as job duties and personmatch to fulfil the responsibilities. Out of 20 interviews, 9 respondents said that they did not observe any differences in the job satisfaction of female and male colleagues. Four interviewees 
did not stipulate any observations and refrained from the answer. Seven respondents noticed some differences in the job satisfaction of females and male employees. They noted that both genders might be dissatisfied but due to different factors. For example, males may be dissatisfied with the salary factor "as they have breadwinner roles in the family." Females may be dissatisfied because of the potential growth opportunities, as sometimes "they see that all top positions are male-dominated". On the contrary, some of the administrative staff females noted that women were more satisfied with their job as it provided a good opportunity to socialize and meet needs for affiliation. Moreover, female academic staff observed that married females seek flexibility due to family circumstances.
The questionnaire asked respondents to evaluate their job satisfaction from 1 to 7 , "1" being "strongly dissatisfied" and "7" being "strongly satisfied." The questionnaire findings showed the results from qualitative data that the majority of employees were satisfied with their job. The following diagram (Figure 3) demonstrates the level of general job satisfaction of the staff calculated by gender. Only one percent of females revealed more dissatisfaction than males. However, the percentage of neutral attitude was the same for men and women. Furthermore, the number of females who were satisfied to a certain extent was more than the males, but the number of satisfied and strongly satisfied employees was more significant for males than females.

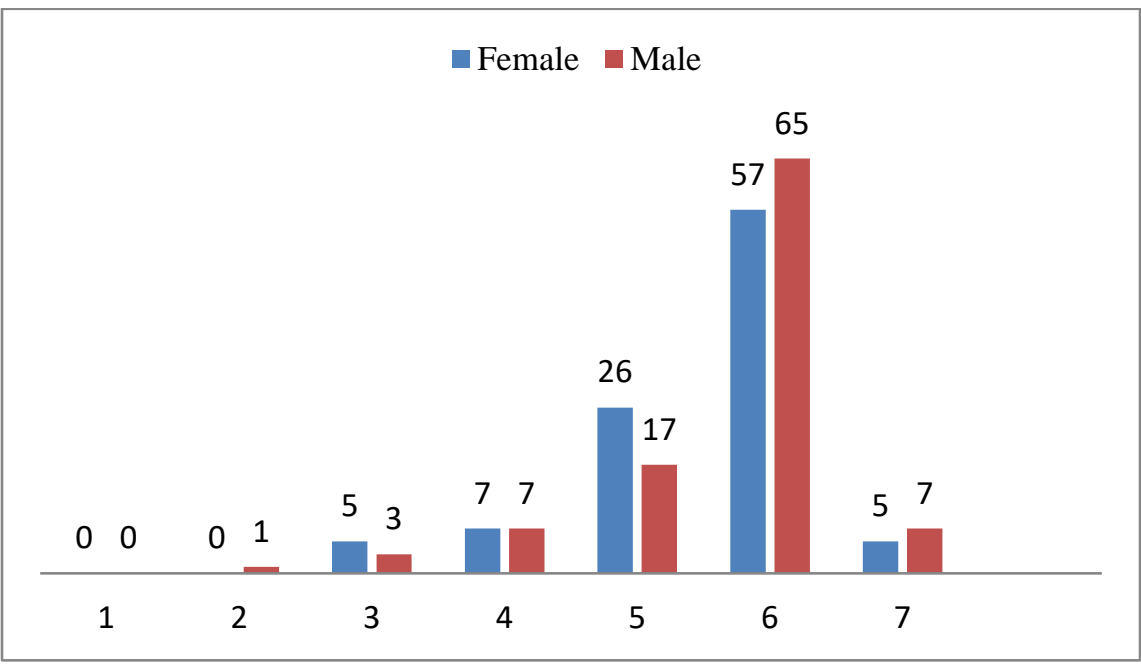

Figure 3: Employees' job satisfaction by gender in percentage.

In the questionnaire, respondents were asked to evaluate 18 factors that contribute to job satisfaction. The scale from 1 to 7 was used to determine the level of satisfaction with each factor. Furthermore, a chi-square test was conducted with the help of STATA to identify whether there are relationships between variables of job satisfaction and gender. The first null hypothesis assumed that there are no relationships between gender and general job satisfaction. The result of Fisher exact indicated $\mathrm{p}$-value $=0.840$ and the null hypothesis could not be rejected. Further tabulation by gender in administrative and academic staff did not identify relationships between variables. Further, the chi test was conducted for other factors of job satisfaction and gender. It identified that the p-value of Fisher exact for personal workspace factor was 0.031 (at 95\% confidence) and, thus, it helps to reject the second null hypothesis and establish that there are relationships between personal workspace satisfaction and gender. There are also relationships between satisfaction with job security (Fisher exact- 0.034) and gender.

The T-test was run using SPSS software to determine whether the results of the mean differences were significant for job satisfaction 
factors and gender. It acknowledged that the results are statistically significant for differences in job satisfaction with personal workspace factors (p-value of .036 all staff and .050 academic staff). Referring to the table of the mean comparisons, females of the whole sample and academic staff were more satisfied than their male counterparts. T-test for females and males in administrative staff determined that the results are statistically significant for satisfaction with relationships with co-workers (p-value of .008) as well as support for additional training and education ( $p$-value .024). It helped to determine that females were more satisfied with the two factors mentioned above. It also demonstrated that differences of the mean scores for general job satisfaction of academic and administrative cohorts by gender were insignificant $\quad(0.870$ and 0.578 , respectively).

In the last question of the survey, respondents were asked what university administration could do to enhance their job satisfaction. The results were processed with QDA Miner, and Table 3 illustrates the frequency of codes by gender. The results demonstrated that there were slight differences in the codes of transparency and consistency in HR management with more concerned males than females. Both expressed the desire to have clearer promotion and appraisal procedures at university. More women paid attention to communication and team building activities, trade union enhancement, more discipline for employees, health insurance conditions, vacation and training and development areas.

Table 3. Code frequency on areas to improve job satisfaction and gender (QDA Miner)

\begin{tabular}{|l|l|l|l|l|}
\hline Codes & Male & Female & Chi-square & P-value \\
\hline Transparency and consistency in HR management & $18.60 \%$ & $19.00 \%$ & 0.709 & 0.4 \\
\hline Restructuring & $4.70 \%$ & $2.50 \%$ & 0.204 & 0.652 \\
\hline Flexibility & $1.20 \%$ & $6.30 \%$ & 4.433 & 0.035 \\
\hline Communication and teambuilding activities & $4.70 \%$ & $7.60 \%$ & 1.448 & 0.229 \\
\hline Trade Union & $1.20 \%$ & $2.50 \%$ & 0.761 & 0.383 \\
\hline Discipline & $2.30 \%$ & $5.10 \%$ & 1.571 & 0.21 \\
\hline Training and development & $4.70 \%$ & $10.10 \%$ & 3.350 & 0.067 \\
\hline Exchange programs & $4.70 \%$ & $3.80 \%$ & 0.002 & 0.969 \\
\hline Teaching specific items to be considered & $8.10 \%$ & $6.30 \%$ & 0.001 & 0.971 \\
\hline Salary and rewards & $19.80 \%$ & $17.70 \%$ & 0.165 & 0.685 \\
\hline Health insurance & $2.30 \%$ & $2.50 \%$ & 0.105 & 0.746 \\
\hline Vacation time & $1.20 \%$ & $2.50 \%$ & 0.761 & 0.383 \\
\hline Research programs & $8.10 \%$ & $3.80 \%$ & 0.672 & 0.412 \\
\hline More allowance for research (time, space, money) & $8.10 \%$ & $6.30 \%$ & 0.001 & 0.971 \\
\hline Canteen (space, prices) & $5.80 \%$ & $2.50 \%$ & 0.569 & 0.451 \\
\hline Workspaces and IT & $4.70 \%$ & $1.30 \%$ & 1.059 & 0.304 \\
\hline
\end{tabular}

In contrast, more males were obsessed with restructuring, exchange programs, teaching specific issues, research programs and allowances for research as well as a canteen, working conditions and IT. Flexibility code also demonstrated some discrepancy between 
females $(5.70 \%)$ and male $(1 \%)$ colleagues. The table also presents the code occurrence in the cases that were tabulated by gender, helping to identify the relationship between codes and gender. The p-value of 0.035 was found in the code of flexibility, which means there are relationships between the gender variable and the code occurrence of flexibility. In the training and development code, the p-value equals to 0.067, which suggests there can be some relationships between the variables of gender and training and development code.

\section{CONCLUSION}

Schulze (2006) stated that the social climate at an organization had the greatest effect on job satisfaction for employees. In fact, all the interviewees considered that the working environment played a significant role in the working life of employees. The ability to socialize at work was more significant to females as it helped them to satisfy their need for affiliation. More females suggested improvements in communication and the need to provide more teambuilding activities. This finding is related to the need for socialization, peer, and family relationships (Millier \& Bellamy, 2014) and a higher satisfaction level for relationships with co-workers.

Bender et al., (2005) stated that flexibility was a critical factor in job satisfaction, but women and men might treat this factor differently. This element was essential for women while choosing job characteristics and it explained the relationship between job satisfaction and gender segregation at work (Bender et al., 2005). It was confirmed by the current study and both males and females evaluated this factor as a top important factor. For female staff, it was generally essential to have a certain degree of flexibility due to the multiple roles in the society as a wife, mother and employee. This particular factor was significant in order to accomplish goals related to job demands and family duties (Okpara et al., 2005). This discrepancy suggests that for the majority of women, it is hard to give up the flexibility factor and they value it much higher than financial rewards.

As per the opportunity to conduct research as a factor that impacts job satisfaction, there were more males (66.70\%) than females (33.30\%) who elaborated on this factor in the interviews. Moreover, a bigger share of male staff members seeks improvement in research programs as stated by the results of the questionnaire. Nevertheless, currently, more males are interested in this aspect. Carli (1998, p.3; cited in Bay et al., 2001) noted that "women are not generally respected as good scholars and may even be viewed as particularly deficient in terms of research and publishing." Females who publish a lot and stay competitive with males are treated as unfeminine by male employees (Carli 1998, p. 3; cited in Bay et al., 2001). Saner \& Eyupoglu (2012) suggested that due to workfamily conflict and difficulty in balancing working and personal life, research and publishing appeared to be more demanding for female employees comparing to their male counterparts.

General job satisfaction analysis by gender did not find major differences between female and male colleagues. These findings are consistent with Toker's (2011) study of academic staff in Turkey, which concluded that gender did not relate significantly to job satisfaction.

The T-test helped to identify that results are statistically significant for differences between male and female satisfaction in such factors as a personal workspace, relationship with coworkers, and support for additional training and education. Females are more satisfied with the factors mentioned above than their male counterparts. Lacy and Sheehan (1997) and Okpara et al. (2005) asserted that women expressed more satisfaction with their relationship with colleagues. The chi-square test confirmed that there are relationships between gender and personal workspace as well as gender and job security satisfaction factors. Regarding these two factors, the second null hypothesis can be rejected. The factor of flexibility revealed relationships between gender and areas of improvement discussed by staff along with satisfaction with the factors of personal workspace, job security, opportunities for training and development, relationship with co-workers. 


\section{RECOMMENDATIONS}

Job satisfaction and its factors may vary for male and female employees, and management must make a periodic reflection on what their employees are satisfied with. Some limitations of the study may reflect the nature of the job satisfaction self-report questionnaire by the respondent, being dependent on employees' judgment and operating on perception levels. The data was collected only at one point in time during summer and from a relatively small sample. The time of data collection coincided with the vacation time of the majority of academic and administrative staff, causing a lower response rate. This study is dedicated to the job satisfaction of university staff and particularly the case of the university, so the extent to which the findings can be generalized to a broader context might be an issue.

For these reasons, job satisfaction is recommended to be measured several times during the academic year to have more objective self-report data. This will help to see variations in job satisfaction and identify factors related to dissatisfaction. It is necessary to do large-scale research for job satisfaction and gender study among universities in Uzbekistan that may have implications for staff effectiveness at work.

\section{REFERENCES}

Abdulla, J., Djebarni, R., \& Mellahi, K. (2011). Determinants of job satisfaction in the UAE. Personnel Review. 40 (1), 126 - 146. Available from: Emerald Insight. http://dx.doi.org/10.1108/00483481111095 555

Abosode, C. (2014). Gender differences in job satisfaction of academic and non-academic staff of Olabisi Onabanjo University. Journal of Education and Practice. 5 (22), 34-41.

Available from

www.iiste.org/Journals/index.php/JEP/articl e/download/14538/14847 .

Bay, D., Allen, M., \& Njoroge, J. (2001). Gender orientation, success and job satisfaction in accounting academia. Advances in Accountability: Regulation, Research, Gender and Justice. 8, 1-20. Available from: Emerald Insight.
<http://dx.doi.org/10.1016/S10417060(01)08003-8.

Bender, K., Donohue, S., \& Heywood, J. (2005). Job Satisfaction and Gender Segregation. Oxford Economic Papers. 57 (3), 479-496. Oxford University Press. Duong, M., (2014). The relationships between demographic characteristics and faculty job satisfaction in Vietnamese Higher Education. European Journal of Research and Reflection in Educational Sciences. 2 (3), 16-27. Available from www.idpublications.org.

Fako, T., Moeng, S., \& Forcheh, N. (2009). Gender differences in satisfaction with the type of work university employees do: Evidence from the University of Botswana. J. Service Science \& Management. 2, 404-417. Available from www.SciRP.org/journal/jssm

Garcia-Bernal, J., Gargallo-Castel, A., MarzoNavarro, M. \& Rivera-Torres, P. (2005). Job satisfaction: empirical evidence of gender differences", Women in Management Review, 20 (4), 279 - 288.

Hundera, M. (2014). Factors affecting academic staff turnover intentions and the moderating effect of gender. International Journal of Research in Business Management. 2 (9), 57-70.

Lacy, F. J. \& Sheehan B.A. (1997). Job satisfaction among academic staff: an international perspective. Higher Education, 34 (3), 305322. Available from: http://www.jstor.org/stable/3448259

Luthans, F. (1998). Organizational behavior. 8th ed. Boston: Irwin McGraw-Hill. MachadoTaylor, M. et al., (2014). Job Satisfaction of Academics: Does Gender Matter? Available from http://www.palgravejournals.com/hep/journal/v27/n3/full/hep20 1334a.html

Mangi, R.A., Soomro, J.H., Ghumro, I.A, Abidi, A.R. \&Jalbani, A.A. (2011). A study of job satisfaction among non-PhD faculty in universities. Australian Journal of Business and Management Research. 1 (7), 83-90.

Millier, K. \& Bellamy, P.J. (2014). The Businesswomen's Association of Uzbekistan: A qualitative study of the emergence and potential influence of women's leadership in Central Asia. Journal of Eastern European 
and Central Asian Research. 1 (1), 1-9. Available from:

https://www.ieeca.org/journal/index.php/JE ECAR/issue/archive

Mustapha, N. \& Ghee, W. (2013) Examining faculty workload as an antecedent of job satisfaction among academic staff of higher public education in Kelantan, Malaysia. Business and Management Horizons. 1(1), 10-16. Macrothink Institute.

Okpara, J.O., Squillace, M., \& Erondu, E.A. (2005). Gender differences and job satisfaction: a study of university teachers in the United States. Women in Management Review. 20 (3), 177-190. Available from: Emerald Insight. http://dx.doi.org/10.1108/09649420510591 852

Oshagbemi, T. (2000). Gender differences in the job satisfaction of university teachers. Women in Management Review. 15 (7), 331 $-343$.

Pandey, D. (2014). Job satisfaction of college teachers in relation to their personal variables. Online International Interdisciplinary Research Journal. 4, 324339. Available from:

www.oiirj.org/oiirj/May2014-specialissue/35.pdf

Reed, S., Kratchman, S.H., \& Strawser, R.H. (1994). Job satisfaction, organizational commitment, and turnover intentions of United States accountants. Accounting, Auditing \& Accountability Journal. 7 (1), 31 58. Emerald Insight Available from http://dx.doi.org/10.1108/09513579410050 371.

Saba, I. (2011). Measuring the job satisfaction level of the academic staff in Bahawalpur Colleges. International Journal of Academic Research in Business and Social Sciences. 1(1). Available from: http://econpapers.repec.org/article/hurijarb s/v_3a1_3ay_3a2011_3ai_3a1_3ap_3a1219.htm.

Sabharwal, M. \& Corley, E. (2009). Faculty job satisfaction across gender and discipline. The Social Science Journal. 46, 539-556. Available from www.sciencedirect.com
Saner, T. \& Eyupoglu, S. (2012). Have gender differences in job satisfaction disappeared? A study of Turkish universities in North Cyprus. African Journal of Business Management. 6 (1), 250-257. Available from http://www.academicjournals.org/AJBM

Schulze, S. (2006). Factors influencing the job satisfaction of academics in Higher Education. Unisa Press, 318-335.

Singh, P., Finn, D., \& Goulet, L. (2004). Gender and job attitudes: a re-examination and extension. Women in Management Review. 19 (7), 345 - 355. Available from: Emerald Insight. http://dx.doi.org/10.1108/09649420410563 403

Soleman, A. (2005). Gender, ethnicity, and job satisfaction among social workers in Israel. Administration in Social Work. 29(3), 7-21. Available from http://www.sciesocialcareonline.org.uk/search?q=subject_te rms\%3A\%22Jewish+people\%22\&page=1\&f_ge ography_taxonomy_term=Middle+East\&f_su bject_terms=job+satisfaction

Toker, B. (2011). Job satisfaction of academic staff: an empirical study on Turkey. Quality Assurance in Education, 19 (2), 156 - 169 Available from Emerald Insight. <http://dx.doi.org/10.1108/0968488111112 5050.

Yapa, P.M.S.P., Rathnayake, R.M., Senanayake, G., \& Premakumara, P. (2014). Effect of demographic factors on job satisfaction of non-academic staff in universities. Proceedings of the 3rd International Conference on Management and Economics. University of Ruhuna, Sri Lanka, 26-27 February 2014. Available from www.mgt.ruh.ac.lk/pubs/pdf/ICME2014_OP _p303.pdf

\section{ABOUT THE AUTHOR}

Olesya Smagina, email: osmagina@wiut.uz

Ms. Olesya Smagina is a Senior Lecturer Westminster International University in Tashkent, Uzbekistan and holds MA in International Business Management. 